\title{
ApoE2 Exaggerates PTSD-Related Behavioral, Cognitive, and Neuroendocrine Alterations
}

\author{
Lance A Johnson', Damian G Zuloaga', Erin Bidiman', Tessa Marzulla', Sydney Weber', Helane Wahbeh ${ }^{2}$ and \\ Jacob Raber ${ }^{*, 1,2,3}$
}

'Department of Behavioral Neuroscience, Oregon Health and Science University, Portland, OR, USA; ${ }^{2}$ Department of Neurology,

Oregon Health and Science University, Portland, OR, USA; ${ }^{3}$ Department of Radiation Medicine and Division of Neuroscience, ONPRC,

Oregon Health and Science University, Beaverton, OR, USA

\begin{abstract}
Apolipoprotein $E(a p o E)$ is an essential component of lipoprotein particles in both the brain and periphery, and exists in three isoforms in the human population: E2, E3, and E4. ApoE has numerous, well-established roles in neurobiology. Most notably, E4 is associated with earlier onset and increased risk of Alzheimer's disease (AD). Although possession of E2 is protective in the context of AD, E2 appears to confer an increased incidence and severity of posttraumatic stress disorder (PTSD). However, the biological processes underlying this link remain unclear. In this study, we began to elucidate these associations by examining the effects of apoE on PTSD severity in combat veterans, and on PTSD-like behavior in mice with human apoE. In a group of 92 veterans with PTSD, we observed significantly higher Clinician-Administered PTSD Scale and PTSD Checklist scores in E2+ individuals, as well as alterations in salivary cortisol levels. Furthermore, we measured behavioral and biological outcomes in mice expressing human apoE after a single stressful event as well as following a period of chronic variable stress, a model of combat-related trauma. Mice with E2 showed impairments in fear extinction, and behavioral, cognitive, and neuroendocrine alterations following trauma. To the best of our knowledge, these data constitute the first translational demonstration of PTSD severity in men and PTSD-like symptoms in mice with E2, and point to apoE as a novel biomarker of susceptibility, and potential therapeutic target, for PTSD.

Neuropsychopharmacology (2015) 40, 2443-2453; doi:10.1038/npp.2015.95; published online 6 May 2015
\end{abstract}

\section{INTRODUCTION}

Posttraumatic stress disorder (PTSD) is a debilitating mental disorder that is characterized by re-experiencing, avoidance, and hyperarousal (American Psychiatric Association, 2013). The detrimental effects of PTSD are often magnified by accelerated development of stress-related medical conditions, and PTSD displays a high comorbidity rate with anxiety and depressive disorders (Gadermann et al, 2012). Following a traumatic event, many people experience traumatic stress symptoms, but rates appear to diminish quickly over the course of a few months (Rubin et al, 2005; Galea et al, 2003). Thus, PTSD has been characterized as a condition in which a positive course of recovery from trauma is impeded (Yehuda and LeDoux, 2007). It has been estimated that close to $90 \%$ of people are exposed to at least one traumatic event, such as rape, assault, disaster, rescue work, or combat, over the course of their lifetime (Kilpatrick et al, 2013). However, PTSD develops only in a subgroup of people exposed to a traumatic event, with the lifetime prevalence of PTSD estimated between 7.8 and $8.7 \%$ (Kessler et al, 1995, 2005), thus

*Correspondence: DrJ Raber, Department of Behavioral Neuroscience, L470, Oregon Health and Science University, Portland, OR 97239, USA, Tel: + I 503494 | 524, Fax: + I 503494 6877, E-mail: raberj@ohsu.edu Received 21 November 2014; revised 23 January 2015; accepted 31 March 2015; accepted article preview online 10 April 2015 supporting a role for genetic risk factors (Pittman et al, 2012; Yehuda et al, 2011).

Why some individuals exposed to trauma develop PTSD and others do not is a longstanding question. Identifying specific genes that are associated with PTSD risk could provide new understanding of the cause of this disorder, and eventually lead to the design of new therapeutics. Several genes within the hypothalamic-pituitary-adrenal (HPA) axis (FKBP5, GCCR, CNR1), dopaminergic (DRD), and serotonergic (SLC6A4) systems have been linked to PTSD (Cornelis et al, 2010). Genes encoding neurotrophins (BDNF), G-protein signaling (RGS2), and lipoproteins have also have been investigated, including the recent association of the $\varepsilon 2$ allele of the gene encoding apolipoprotein E (apoE) with PTSD risk and symptomatology (Freeman et al, 2005; Kim et al, 2013). ApoE is an essential component of lipoprotein particles both in the brain and in the periphery, and exists in three isoforms in the human population: apoE2 (E2), apoE3 (E3), and apoE4 (E4) (Mahley and Rall, 2000). ApoE has numerous roles in behavioral and cognitive functions, including regulation of anxiety and cognitive performance during normal aging and in the context of neurodegenerative disease (Raber et al, 2003; Raber, 2007; Verghese et al, 2011). Several neurobiological functions associated with PTSD have been shown to be modulated by apoE isoform, including hippocampal volume (Hostage et al, 2013), cognitive impairment (Caselli et al, 
2007), and neuroendocrine alterations related to the HPA axis (Gil-Bea et al, 2010; Peskind et al, 2001; Raber et al, 2000).

Compared with E3, E4 has been associated with decreased brain metabolism (Reiman et al, 2004), deficient repair following injury (Laskowitz et al, 1998), and earlier onset and increased risk of Alzheimer's disease (AD), whereas E2 is generally protective (Farrer et al, 1997). However, E2 was recently associated with an increase in the risk and severity of PTSD in two studies (Freeman et al, 2005; Kim et al, 2013). In the first study, E2 was associated with an increased risk of PTSD and moderated the interaction between PTSD and alcohol use (Kim et al, 2013). In the second, E2 was associated with decreased memory function and more severe re-experiencing symptoms in chronic, combat-related PTSD subjects (Freeman et al, 2005). Consistent with these two human studies, we recently demonstrated that homozygous mice expressing only human E2 exhibit impaired extinction of contextual fear memory (Olsen et al, 2012). Impaired extinction of fear memory has been proposed to reflect the processes underlying the recurring and re-experiencing symptoms of PTSD (Jovanovic and Ressler, 2010).

Although this recently identified link between apoE and PTSD is of great interest, the biological processes underlying this association remain unclear. In the current study, we sought to elucidate these associations by investigating the effects of apoE on symptomatology in humans with PTSD, as well as examining PTSD-like behavioral and physiological changes in a mouse model of human apoE.

\section{MATERIALS AND METHODS}

\section{Participants, Cortisol Collection, ApoE Measurement, and $A P O E$ Genotyping}

Human data were collected as part of a larger clinical trial $(n=114)$. Participants were mostly male combat veterans from the Vietnam Era. Detailed descriptions of participants and data collection are available in the Supplementary Materials and Methods section. The study was approved by the Portland Veterans Administration Medical Center and Oregon Health and Science University institutional review boards. Written informed consent was obtained from all subjects. Data used in this analysis included genetic data for 110 individuals, 6 of whom were female (all E3/E3) and their data were not included in this study; complete clinical measures for 92 men; and cortisol measurements for 82 of these individuals. Salivary cortisol was collected at waking, $30 \mathrm{~min}$ after waking, and bedtime using Sarstedt Salivettes (Sarstedt, Germany) on two consecutive weekdays, as described previously (Wahbeh et al, 2008; Wahbeh and Oken, 2013). Participants fasted for the waking and 30-min sample, and the importance of collecting the sample immediately upon waking and exactly $30 \mathrm{~min}$ after was stressed to the participants. Participants recorded their saliva collection times on a data sheet. Plasma was collected from unfasted individuals at the screening visit, and apoE concentrations were determined in diluted plasma (1:300) using a commercial assay (Abcam, Cambridge, MA). APOE genotype was determined from whole blood DNA samples, and cortisol values were quantified in duplicate with enzymelinked immunoassay (Salimetrics, State College, PA), by the Oregon Clinical and Translational Research Institute.

\section{Experimental Animals}

Mice expressing human apoE isoforms under control of the mouse apoE promoter (targeted replacement mice) were backcrossed for at least 10 generations to the C57BL/6 background (Knouff et al, 1999; Sullivan et al, 1997, 1998). Mice were fed normal chow diet ad libitum (Prolab IsoPro RMH 3000; Agway). All analyses were carried out in mice 4-5 months of age. Only male mice were used for the current study. All procedures were in compliance with the National Institutes of Health Guide for the Care and Use of Laboratory Animals and with IACUC approval at Oregon Health and Science University.

\section{Chronic Variable Stress}

To simulate the variable, extreme, and chronic nature of conditions experienced by military personnel in combat, we used a model of chronic variable stress (CVS) (Goswami et al, 2013). Mice were exposed daily to multiple distinct stressors over the course of five consecutive days using a modified version of a previously described protocol (McGuire et al, 2010). Mice were exposed daily to two of the following stressors over the course of the 5-day period: (1) Cold water swim. Mice were placed in a beaker (diameter $12 \mathrm{~cm}$, height $24 \mathrm{~cm}$ ) filled with cold water $\left(16-18^{\circ} \mathrm{C}\right)$ to a height of $12 \mathrm{~cm}$ for a period of $3 \mathrm{~min}$. (2) Restraint for $15 \mathrm{~min}$. (3) Food deprivation, overnight (12 h). (4) Intermittent white noise $(300-10000 \mathrm{~Hz})$ was generated using white noise generators (Kinder Scientific) for $1 \mathrm{~h}$. (5) Wet cage. Three hundred milliliters of water was added to the bedding of each cage and mice remained in the wet cage for a period of $3 \mathrm{~h}$. (6) $45^{\circ}$ Cage tilt. Cages were removed from the ventilation rack and placed on a $45^{\circ}$ angled cage holder for $3 \mathrm{~h}$. (7) Predator threat (odor) for $5 \mathrm{~min}$. Odor exposure was performed by adding $10 \mu \mathrm{l}$ of liquid odorant (5\% 2,5dihydro-2,4,5-trimethylthiazoline; TMT) to two pieces of filter paper $\left(2 \times 2 \mathrm{~cm}^{2}\right)$ affixed to the left and right test chamber walls before placing the subject into the chamber. TMT is an active compound derived from fox scent glands and elicits a prey fear response in mice (Ayers et al, 2013; Fendt and Endres, 2008).

\section{Anxiety-Like Behavior, Nest Building, and Activity Monitoring}

Anxiety-like behavior was measured using the elevated zero maze as described (Johnson et al, 2014). Nest building was measured using an established protocol (Deacon, 2006), and activity was monitored using home-cage activity sensors (Biobserve, St Augustin, Germany).

Fear Memory and Extinction: Hippocampus-Dependent Declarative Memory

Fear acquisition and extinction were analyzed using a Med Associates mouse fear conditioning system, and hippocampus-dependent spatial memory was tested using a modified version of the Morris water maze, similar to a previously described protocol (Johnson et al, 2014). 


\section{Biochemical Analyses}

Mice were administered a ketamine-xylazine-acepromazine cocktail and intracardially perfused with $20 \mathrm{ml}$ PBS. The adrenal and pituitary glands were carefully dissected and brains were removed. The right hemisphere was regionally dissected as described (Spijker, 2011), and dissected tissues were immediately frozen in liquid nitrogen and stored at $-80^{\circ}$ $\mathrm{C}$ until analysis. Human apoE protein levels were measured in plasma and RIPA-homogenized tissues using a commercially available ELISA (Abcam). Corticosterone was measured in plasma using the ImmuChem Double Antibody Corticosterone 125I RIA Kit (MP Biomedicals, Orangeburg, NY).

\section{Statistical Analyses}

Data are expressed as mean \pm SEM. Multiple groups and/or multiple time points were analyzed using repeated-measures or multivariate ANOVA, followed by paired or unpaired t-tests using GraphPad Prism (San Diego, CA) or SPSS software (Chicago, IL).

For additional information, see Supplementary Materials and Methods.

\section{RESULTS}

\section{Mice with Human E2 Exhibit Impaired Extinction of Fear Memory}

As deficits in the extinction of contextual fear memory likely contribute to the pathophysiology of PTSD (Jovanovic et al, 2009; Maren, 2001), we examined contextual fear extinction in a mouse model of human apoE (Figure 1a) (Knouff et al, 1999; Sullivan et al, 1997, 1998). Acquisition of contextual conditioned fear was determined by comparing the percentage of time mice spent freezing during a 1-minute baseline period and the time following a mild foot shock. E2/E2 mice showed a slower increase in freezing rates during training compared with all groups except E2/E3 (Figure 1b) $(P<0.05)$. However, by the conclusion of the training session (final minute), the levels of freezing did not differ by genotype (Figure 1c), and all groups showed significantly increased freezing following shock $(P<0.001)$, suggesting universal acquisition of the conditioned fear (Figures $1 \mathrm{~b}$ and c). Additionally, there was no difference in activity response during the foot shocks, suggesting a similar sensitivity and reactivity to the shock (Figure 1d). E2/E2 mice showed a significantly slower decline in freezing over 4 days of contextual fear extinction compared with all other groups (Figure 1e) $(P<0.05)$. Additionally, the rate of extinction, measured as the slope of the percent time freezing across all trials, was significantly slower in E2/E2 mice compared with all other groups (Figure 1e) $(P<0.05)$.

\section{Cognitive and Behavioral Impairments in Mice with E2 Following Conditioned Fear Exposure}

To assess the effects of fear conditioning stress on nest building behavior, we rated nest construction in the home cage at baseline and following fear conditioning (Figure 2a). At baseline, there were no differences in the complexity of nests constructed (Figure 2b). However, following the stress of fear conditioning, E2/E2 mice constructed less complex nests compared with other groups (Figure $2 \mathrm{c})(P<0.05)$, demonstrating a disturbance in typical home-cage behavior.

To determine whether the apoE isoforms modulate hippocampus-dependent cognitive function following a traumatic event, we measured long-term spatial memory before and after fear conditioning stress using the water maze. Before the stress, mice completed training in the visible and first hidden sessions. There were no differences in time to reach the platform or swim speed during the visible platform training, indicating intact task learning, motivation, and sensorimotor skills among all genotypes (Figure $2 \mathrm{~d}$, Visible). Likewise, there was no significant effect of $A P O E$ genotype on learning curves to locate the hidden platform (Figure 2d, Hidden). Seventytwo hours after training to locate the first hidden platform location (session 8), mice were given a test of long-term memory retention (Memory Test 1). All mice, regardless of $A P O E$ genotype, showed a preference for the target quadrant, suggesting robust long-term memory (Figure $2 \mathrm{e}$ ).

Next, we examined the effects of stress on long-term memory in these same animals. To avoid the potential influence of varying degrees of memory retention, that is, a 'test-retest' effect, mice were trained to locate a new platform location. Seventy-two hours following the last training trial (session 12), mice were exposed to the fear conditioning stress, and immediately administered a memory test (Memory Test 2). Mice with E2 (E2/E2, E2/E3, and E2/E4) failed to show a preference for the target quadrant during this stress-paired memory test (Figures $2 \mathrm{f}$ and $\mathrm{g}$ ).

\section{CVS - A Model of Combat Related PTSD - Increases Anxiety and Causes Behavioral and Circadian Disturbances in E2+ Mice}

CVS is a model for many stress-related disorders, including PTSD. In this study, we exposed mice to a different stressor daily over subsequent days to simulate the prolonged and unpredictable stress conditions experienced by military personnel in front-line positions (Supplementary Figure 1A) (Goswami et al, 2013). At baseline, mice homozygous for E2 were less anxious, as measured in the elevated zero maze $(P<0.001)$. Following CVS, however, E2/E2 mice showed a marked increase in a measure of anxiety, as evidenced by significantly less time spent in the open (anxiogenic) area (Figure 3a). E2/E2, E2/E3, and E3/E3 mice all showed significant increases in anxiety-like behavior following CVS $(P<0.05)$. Conversely, mice with E4 (E3/E4, E4/E4, and E2/ E4) did not show changes in anxiety-like behavior after the CVS exposure (Figure 3a).

Activities of daily living (ADL) are often disrupted during PTSD (Zatzick et al, 2008), and typical mouse behaviors such as nest building reflect general well-being and may share some psychiatric features with measures of ADL in humans (Deacon, 2012; Jirkof, 2014). CVS reduced nesting scores in all groups compared with baseline (Figures $3 \mathrm{~b}$ and c) $(P<0.05)$. E2/E2 mice were particularly sensitive, as they showed lower nesting scores after CVS than any other group except E2/E3 (Figure 3c) $(P<0.05)$.

PTSD is often associated with sleep disturbances (Germain et al, 2008). To determine the effects of apoE on traumainduced circadian rhythms, we measured circadian homecage activity of singly housed mice before, during, and after CVS (Figure 3d). There were no differences in the light 
a

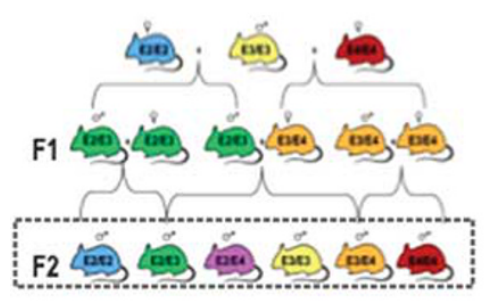

b

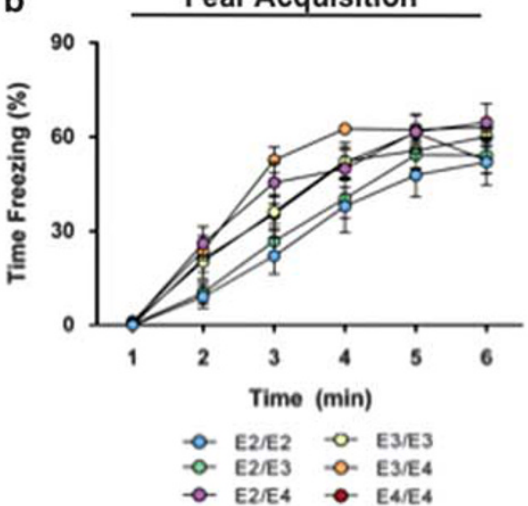

c

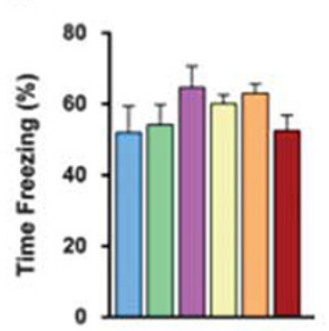

d

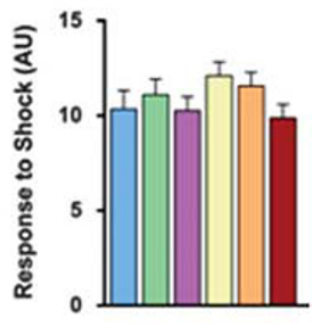

e

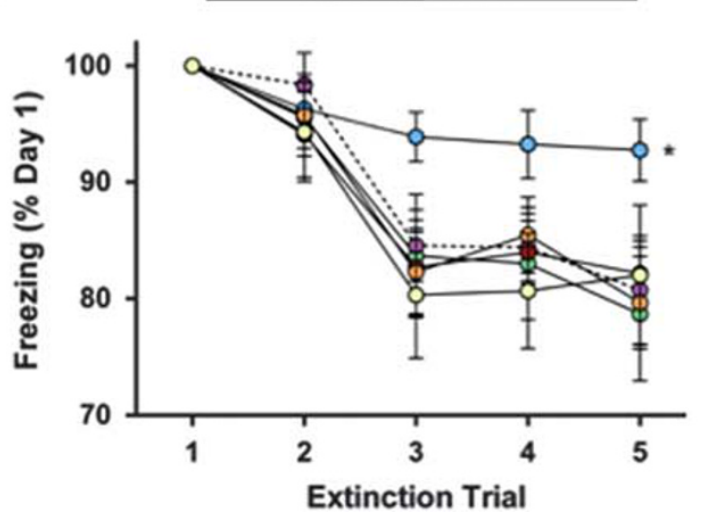

f

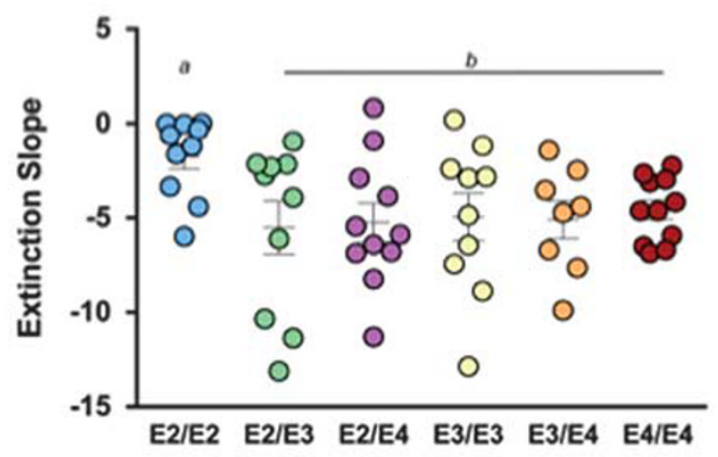

Figure I Impaired extinction of fear memory in E2/E2 mice. (a) Experimental animals. Mice expressing human apolipoprotein E (apoE) were crossed to generate the six APOE genotypes. Male mice from the F2 generation (box) were used in this study. (b) All groups demonstrate robust acquisition of conditioned fear, as shown by an increase in freezing across the fear conditioning session. (c) There was no difference in time spent freezing by the conclusion of the fear conditioning session (average freezing during the final minute). (d) No differences in sensitivity to the aversive stimulus were observed, as noted by the activity response during the mild foot shocks. (e and f) E2/E2 mice show impaired extinction of the conditioned fear memory, as evidenced by a slower decline in freezing (slope of extinction curve) in response to the context; $n=9-12$. Groups labeled with dissimilar letters are significantly different ( $p<0.05$, analysis of variance (ANOVA) followed by $t$-test).

phase, dark phase, or total activity during the 4 days of baseline readings, or during the week of CVS (Supplementary Figures $1 \mathrm{~B}$ and $\mathrm{C})$. However, we observed a significant effect of $A P O E$ genotype on activity after trauma $(P<0.001)$. During the week following CVS, E2/E2 and E2/E3 mice were hyperactive during the active (dark) and inactive (light) phases compared with other genotypes $(P<0.001)$ (Figure 3e). Furthermore, E2/E2 mice were the only group to show increased activity during the posttrauma light cyclea mouse's normal inactive phase-compared with baseline (Supplementary Figure 1D) $(P<0.05)$, possibly reflecting a disruption of normal sleep patterns.

\section{Neuroendocrine and Physiological Alterations in E2+ Mice Following Stress}

Impairments in the HPA axis, including alterations in the stress hormone cortisol, have been proposed to contribute to PTSD pathophysiology (Pitman et al, 2012; Yehuda and LeDoux, 2007). We measured plasma corticosterone concentrations in mice before and after an acute stressor (fear conditioning). There were no differences in plasma corticosterone during baseline (Figure 4a, left). However, compared with mice without, mice with $\mathrm{E} 2$ tended to have elevated plasma corticosterone in response to the acute stressor, and this increase reached significance in E2/E2 and E2/E4 mice (Figure $4 \mathrm{a}$, middle) $(P<0.05)$. Following CVS, plasma corticosterone concentrations were further elevated in all groups following an acute stressor, and again tended to be higher in mice with $\mathrm{E} 2$, although this effect only reached significance in E2/E3 mice (Figure $4 \mathrm{a}$, right) $(P<0.05)$.

Exposure to chronic stress frequently increases adrenal weight, and adrenal hypertrophy can indicate a chronically active HPA axis (Herman et al, 1995; Ulrich-Lai et al, 2006). There was no effect of APOE on the weight of adrenal glands following fear stress ( 5 days of fear conditioning/extinction) (Figure 4b, left). Following CVS, all groups showed significant adrenal enlargement compared with their respective adrenal mass following fear stress $(P<0.001)$. This increase was most pronounced in E2/E2 and E2/E3 mice, as they had significantly larger adrenal glands compared with all other groups following CVS (Figure $4 \mathrm{~b}$, right) $(P<0.001)$.

ApoE expression may influence HPA axis function, as it has been implicated as a modulator of steroidogenesis in the adrenal gland (Reyland et al, 1991; Thorngate et al, 2002; Zofková et al, 2002). In plasma, E2/E2 mice had markedly elevated apoE concentrations. Heterozygous expression of E2 (E2/E3 and E2/E4) resulted in higher plasma apoE levels compared with mice without E2, whereas E4/E4 mice had lower levels than all other groups with the exception of E3/E4 


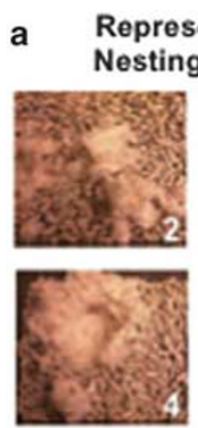

b

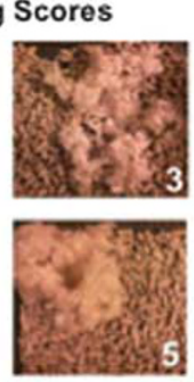

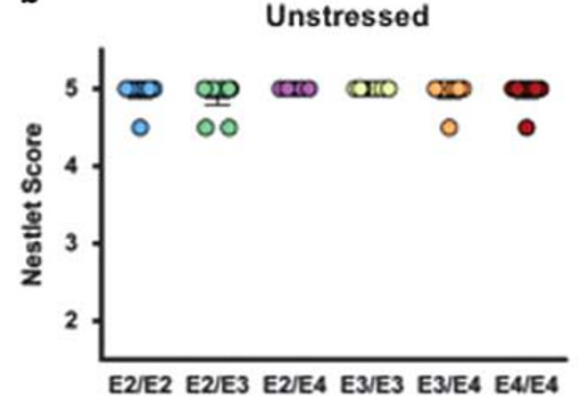

c

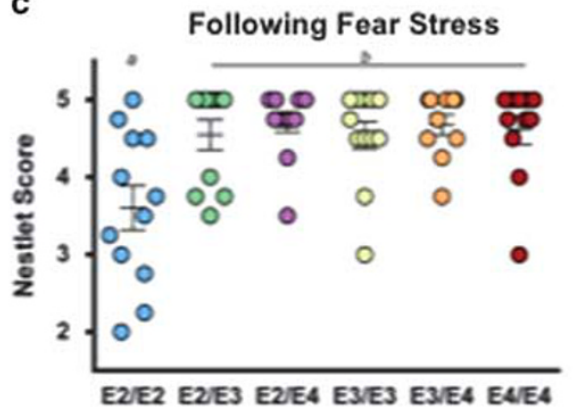

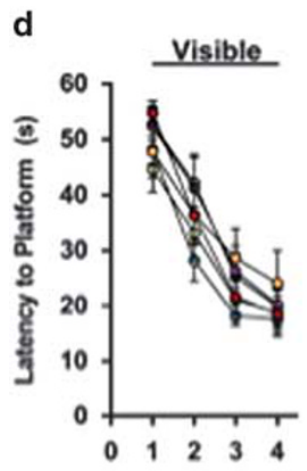

f

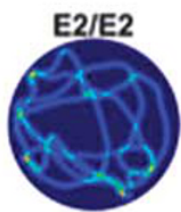

E3/E3

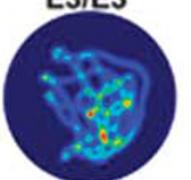

Hidden
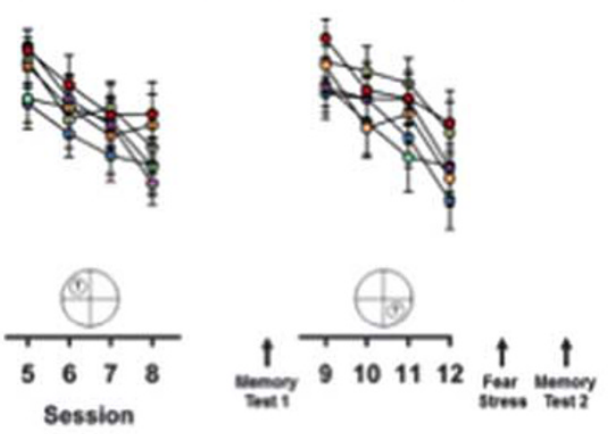

e

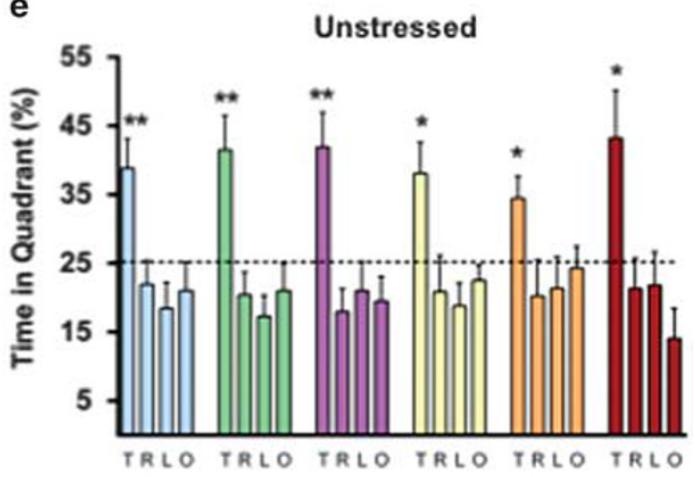

g

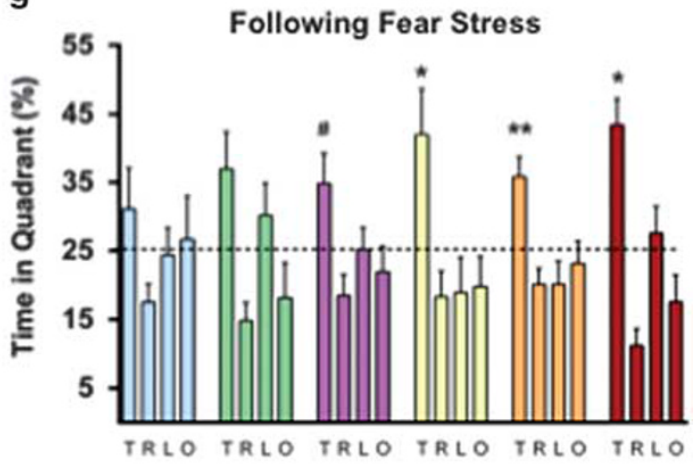

Figure 2 Fear stress disrupts nesting behavior and impairs hippocampus-dependent memory in E2 mice. (a) Representative images of nest building and corresponding scores. (b) Nesting scores did not differ by APOE genotype when mice were given $48 \mathrm{~h}$ to construct a nest in their home cage under normal, unstressed conditions. (c) When given $48 \mathrm{~h}$ immediately following fear stress, E2/E2 mice constructed less complex nests. (d) Learning curves during the Visible and Hidden sessions of the water maze were similar between all groups. (e) Long-term spatial memory was measured $72 \mathrm{~h}$ after training session 8 (Memory Test I). All mice, regardless of APOE genotype, showed a preference for the target quadrant during the unstressed probe trial, indicating robust memory. (f) Seventy-two hours after training for a new platform location, long-term spatial memory retention was measured immediately after mice were exposed to a fear stress. Representative heat maps demonstrate inaccurate search patterns during the poststress memory test in mice with E2. (g) Mice with E2 failed to show preference for the target quadrant following fear stress, suggesting impaired hippocampus-dependent, long-term memory following a traumatic experience; $n=9-12$ per group. Groups labeled with dissimilar letters are significantly different $(p<0.05$, analysis of variance (ANOVA) followed by $t$-test). (e and g) ${ }^{*} P<0.05$ for $T$ vs $R, L, O$; ${ }^{*} p p<0.0$ I for T vs R, L, O; ${ }^{\#} p<0.05$ for T vs R, O, $p=0.08$ T vs L).

(Figure 4c). We then estimated tissue apoE expression by measuring total apoE protein levels in the detergent-soluble fraction of several tissues critically involved in the fear conditioning stress response. ApoE concentrations in the adrenal glands, pituitary glands, and amygdala were all higher in the presence of E2, particularly E2/E2 mice (Figures 4d and f).

E2 is Associated with Increased PTSD Severity and Alterations in Salivary Cortisol Concentrations in Combat Veterans

We next assessed the effects of E2 on PTSD severity in a group of 114 combat veterans enrolled in the VetMind study
(Figure 5a). Genetic data was available for 110 of these individuals, and the allele frequency was 5.3\% for E2, 79.8\% for E3, and $14.9 \%$ for E4, which is similar to previously reported $A P O E$ allele frequencies in the United States general population (Raber et al, 2004).

To examine the effect of APOE on the severity of PTSD symptomatology, we analyzed participants for which complete clinical measures were available $(n=92)$. These 92 veterans with PTSD had the following genotypes: E2/E3 (9), E3/E3 (57), and E3/E4 (26). When grouped by APOE genotype, participants did not differ in age, years of service, time since the traumatic event, sleep quality, or in assessments of lifetime 
a

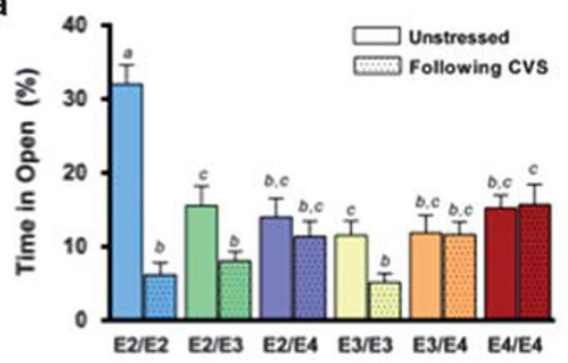

b

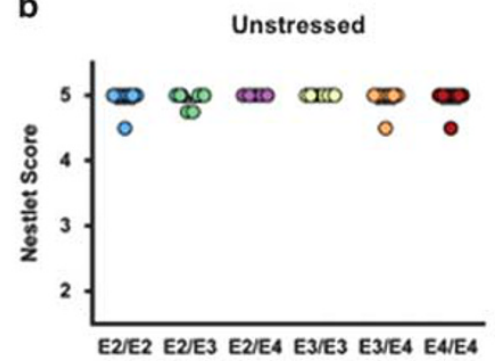

C

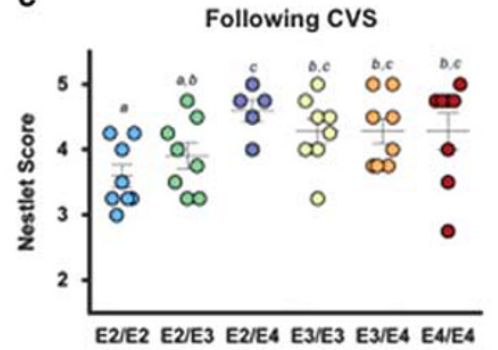

d
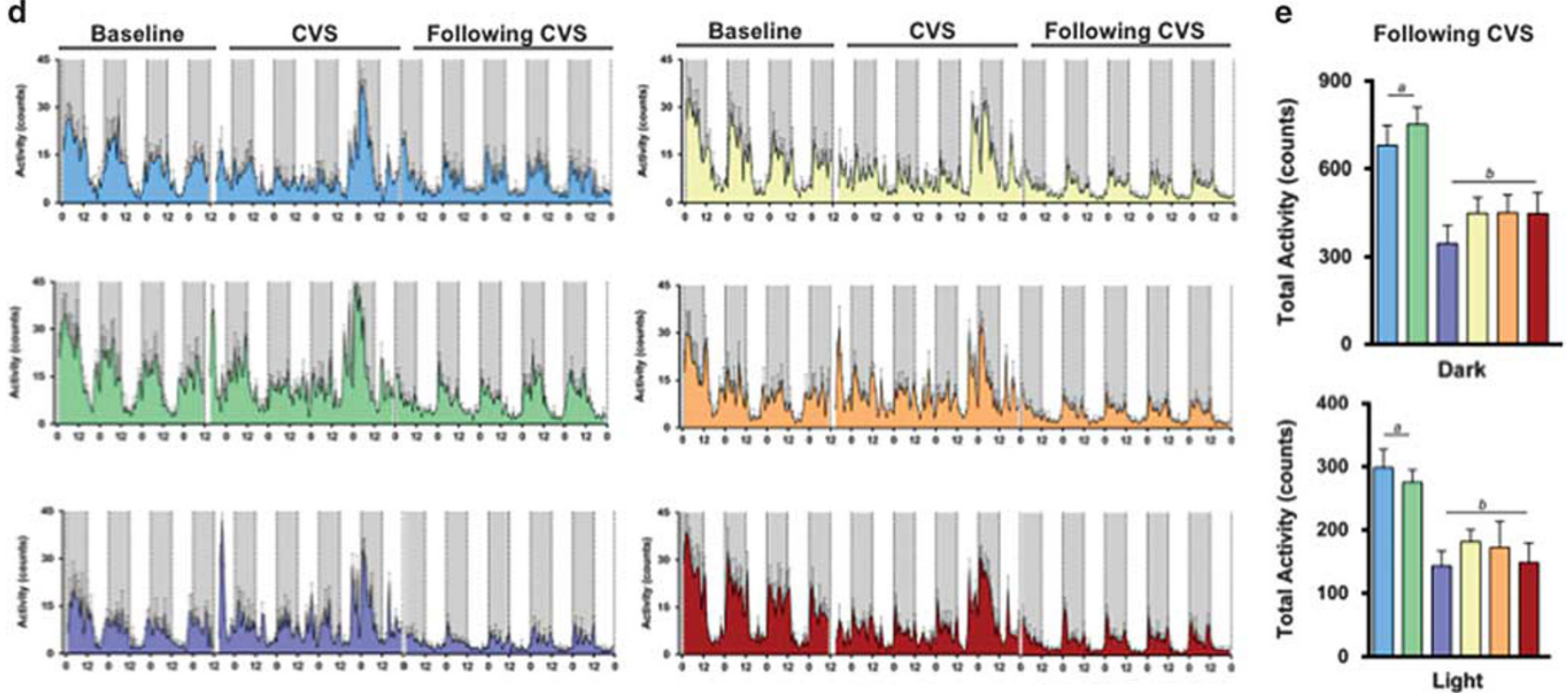

Figure 3 Chronic variable stress increases anxiety and causes behavioral and circadian disturbances in E2/E2 and E2/E3 mice. (a) E2/E2, E2/E3, and E3/E3 mice all showed significant increases in anxiety-like behavior following chronic variable stress (CVS), as evidenced by a significantly lower time spent in the open (anxiogenic) area of the elevated zero maze. E2/E2 mice, in particular, showed a marked increase in anxiety following CVS. Conversely, mice with E4 (E3/E4, E4/E4, and E2/E4) did not show changes in anxiety after CVS. (b) Nesting scores did not differ by APOE genotype under normal, unstressed conditions. (c) Following CVS, all mice constructed significantly less complex nests than at baseline. E2/E2 mice, and to a lesser degree E2/E3 mice, constructed less complex nests following CVS compared with other groups. (d) Home-cage activity was recorded for individual mice during a 4- day acclimation period (baseline), 5 days of CVS, and for 5 days after trauma (following CVS). (e) E2/E2 and E2/E3 mice were hyperactive during both the dark (active) and light (inactive) cycles following CVS. Groups labeled with dissimilar letters are significantly different $(p<0.05$, analysis of variance (ANOVA) followed by $t$-test).

or combat-specific traumatic exposure as estimated by the Life Events Checklist and Combat Exposure Scale (Supplementary Table 1). E2/E3 individuals scored significantly higher on both the PTSD Checklist (PCL) and the Clinician-Administered PTSD Scale (CAPS), compared with those with E3/E3 and E3/ E4 genotypes (Figures 5b and c). E2/E3 subjects scored an average of $64.1 \pm 4.2$ on the PCL compared with $54.3 \pm 9.8$ and $53.1 \pm 10.5$ for individuals with $\mathrm{E} 3 / \mathrm{E} 3$ or $\mathrm{E} 3 / \mathrm{E} 4$ genotype, respectively. Individuals with an E2/E3 genotype scored an average of $80.1 \pm 7.8$ on the CAPS, compared with $66.6 \pm 13.3$ and $65.9 \pm 14.4$ for individuals with E3/E3 or E3/E4 genotype, respectively. Although total CAPS scores were higher in E2/E3 individuals, scores for the three specific DSM-IV CAPS cluster symptoms of re-experiencing, avoidance, and hyperarousal did not statistically differ between the groups (Supplementary Table 2).

PTSD has been associated with alterations in the normal diurnal fluctuation of cortisol levels in certain populations (Yehuda et al, 2005). We examined salivary cortisol levels in 82 individuals with the following genotypes: E2/E3 (8), E3/E3 (48), and E3/E4 (26). Cortisol levels at waking and bedtime did not significantly differ by genotype. However, while E3/
E3 and E3/E4 individuals exhibited clear changes in cortisol levels across the day-significant increases in cortisol concentrations $30 \mathrm{~min}$ after waking and a significant decrease at bedtime-E2/E3 individuals failed to show such a rhythm. Although salivary cortisol levels tended to be lower at bedtime in E2/E3 individuals $(P=0.06$ compared with waking), E2/E3 individuals failed to show an increase in cortisol levels 30 min after waking, as was seen in E3/E3 and E3/E4 participants (Figures $5 \mathrm{~d}$ and e). Additionally, APOE genotype was associated with varying levels of plasma apoE in the direction of E2/E3 $>$ E3/E3 $>$ E3/E4 (Figure 5f).

\section{DISCUSSION}

In the current study, we show that several PTSD-like behavioral, cognitive, and neuroendocrine alterations are more pronounced in mice expressing human E2. These disruptions include a resistance to fear memory extinction in addition to hippocampus-dependent cognitive impairment, increases in anxiety-like behavior, and circadian and nesting disturbances following a stressful event. Furthermore, we 
a

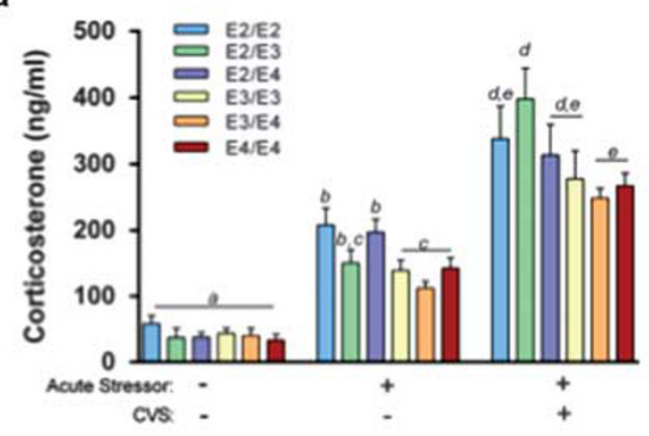

b

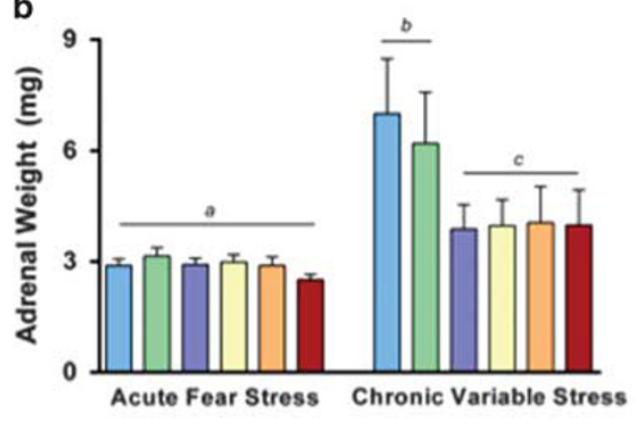

C

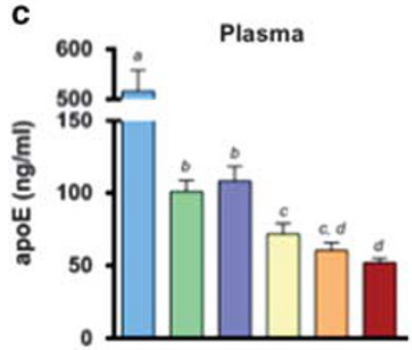

d

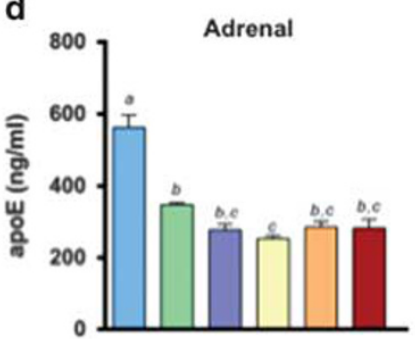

e

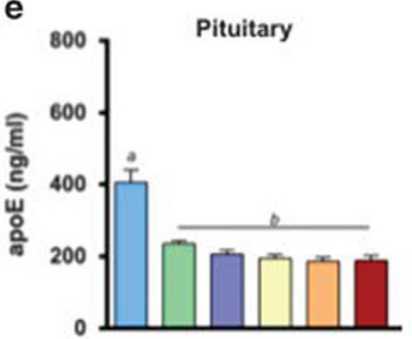

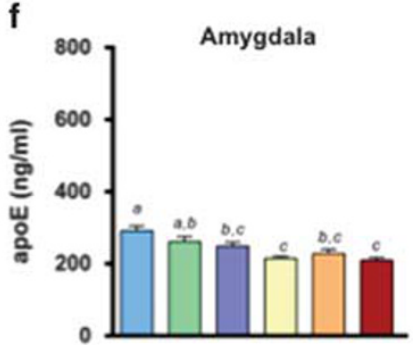

Figure 4 Neuroendocrine and physiological alterations in E2 mice following stress. (a) Mice with E2 tended to have elevated plasma corticosterone concentrations following an acute stressor, as well as following an acute stressor after chronic variable stress (CVS). (b) Adrenal gland weight increased following CVS, most markedly so in E2/E2 and E2/E3 mice. (c-f) E2/E2 mice had elevated apolipoprotein E (apoE) concentrations in the plasma, adrenal glands, pituitary gland, and amygdala. Groups labeled with dissimilar letters are significantly different $(p<0.05$, analysis of variance (ANOVA) followed by $t$-test).

a
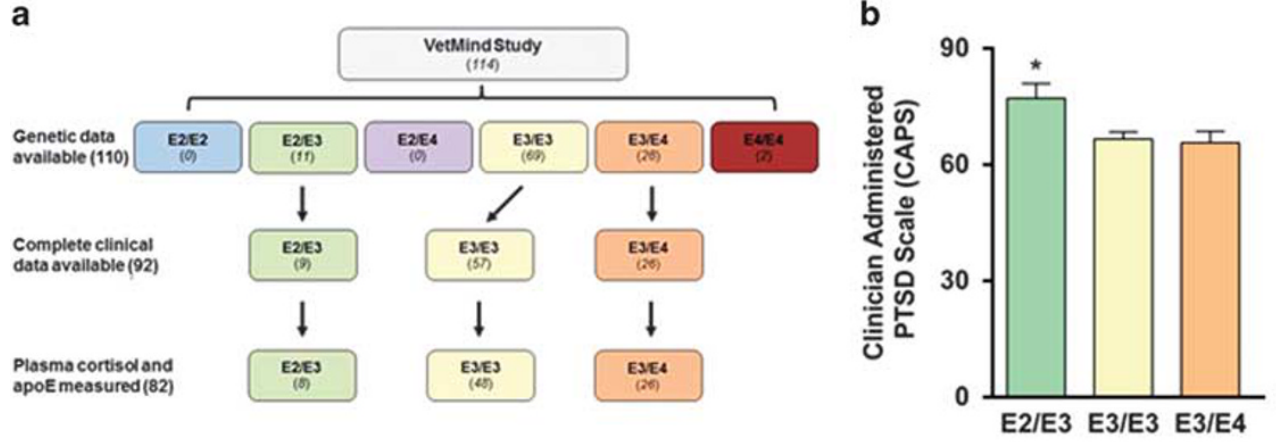

d

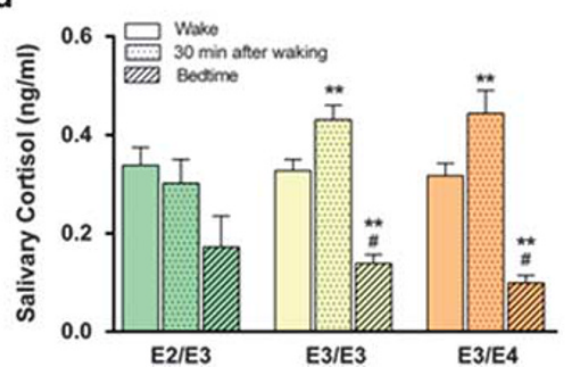

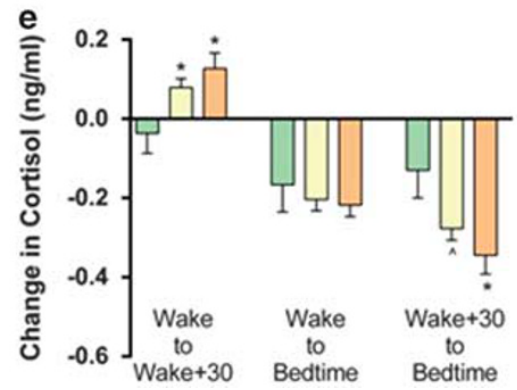

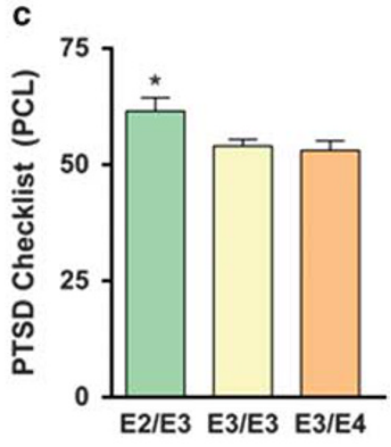

$\mathbf{f}$

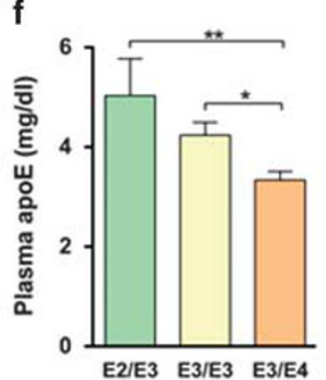

Figure 5 Symptom severity and salivary cortisol levels in veterans with posttraumatic stress disorder (PTSD). (a) VetMind participant flow chart. Participants in the VetMind clinical trial were genotyped for APOE, and PTSD symptomatology, salivary cortisol, and plasma apolipoprotein E (apoE) levels were analyzed. (b and c) In a group of veterans diagnosed with PTSD, individuals with E2/E3 genotype had higher PTSD Checklist (PCL) and Clinician-Administered PTSD Scale (CAPS) scores compared with those with E3/E3 or E3/E4 genotype. (d) E2/E3 individuals did not show an increase in cortisol 30 min after waking as did E3/E3 and E3/E4 individuals, suggesting a potential flattening of the normal diurnal fluctuation in salivary cortisol concentrations. (e) Mean changes in cortisol concentrations across the day. ( $f$ ) Plasma apoE concentrations in (non-fasted) veterans with PTSD. (b and c) $* P<0.05$, analysis of variance (ANOVA) followed by $t$-test. (d) $* P<0.05$, waking vs 30 min after waking; ${ }^{*} p<0.05,30$ min after waking vs bedtime, $t$-test. (e and $f$ ) $* p<0.05, * * p<0.0$ I, $\wedge p=0.058, A N O V A$ followed by t-test. 
demonstrate more severe PTSD symptoms and alterations in salivary cortisol in combat veterans with E2. Taken together, these results establish an interspecies demonstration of exaggerated PTSD symptomatology in the presence of E2.

Given the striking effects on PTSD symptomatology in our cohort of veterans, we turned to a mouse model of human apoE to further examine the effects of $A P O E$ on various neuropsychological phenomena associated with PTSD. To our knowledge, this is the first mouse model of human apoE to examine PTSD-like behavioral, cognitive, and physiological outcomes. To mimic the characteristics of our cohort of veterans, who were all men and whose median age was 21 years at the time of the traumatic incident, we used young adult male mice (4-5 months of age). Although the vast majority of human apoE mouse studies use only homozygous mice, it is very difficult to recruit a sufficient number of E2/E2 participants (genotype frequency <1\%) (Raber et al, 2004). For this reason, and to dissect out specific isoform contributions and potential opposing effects (for instance, in E2/E4 individuals), we included all six $A P O E$ genotypes in our animal model.

Abnormal regulation of fear is a core feature of PTSD, and patients suffering from the disorder exhibit deficits in learning safety in the absence of threat. Much like exposure therapy is applied to PTSD patients in the clinic, this phenomenon is commonly modeled in rodents using fear extinction (Kaouane et al, 2012; McGuire et al, 2010; Rau et al, 2005). Consistent with our data showing more severe PTSD symptoms in E2+ veterans, we confirmed deficits in fear extinction in E2/E2 mice (Olsen et al, 2012), suggesting that an abnormal processing of fear memory may underlie the apparent sensitivity of $\mathrm{E} 2+$ individuals to trauma. Anxiety and avoidance in patients with PTSD can also be modeled in mice using the elevated zero maze. We observed increases in anxiety-like behavior in E2/E2, E2/E3, and E3/E3 mice following CVS, and this increase in anxiety was particularly marked in E2/E2 mice. Interestingly, all the mice expressing E4 (E3/E4, E4/E4, and E2/E4) were resistant to this trauma-induced increase in anxiety-like behavior. Previous research in our lab and others suggest that mice and humans with E4 are generally more anxious (Raber, 2007). In this study, possession of E4 appeared to protect against trauma-induced increases in anxiety, even in mice coexpressing E2. This may suggest a possible exaggeration by E2 (and conversely a buffering by E4) of the anxiogenic effects of CVS. Taken together with evidence in the context of traumatic brain injury (TBI), these results raise an interesting question: how is it that E4 appears to be poorer at negotiating physical trauma (TBI, stroke) (Shi et al, 2014; Zhou et al, 2008), but perhaps more efficient at rectifying the psychological trauma of PTSD?

Another prominent feature of PTSD is memory disturbances, although these disturbances can vary widely. For instance, intrusive memories of the traumatic event fall under the re-experiencing symtpoms, whereas avoidance criteria include an inability to recall critical aspects of the trauma. Additionally, those suffering from PTSD often describe routine memory problems with emotionally neutral material (Samuelson, 2011). PTSD has also been associated with diminished hippocampal volume (Smith, 2005) and function (Shin et al, 2006). Stress can significantly affect memory, and evidence suggests that stress and $A P O E$ interact to affect memory (Peavy et al, 2007). We show that when challenged with a memory test immediately after a fear stress, mice with E2 demonstrate relative impairments in long-term hippocampus-dependent memory. These E2-associated deficits in poststress memory recall occurred despite similar learning curves and similar memory retention in unstressed conditions. These data suggest that possession of E2 imparts a susceptibility to stress-induced impairments in memory, a finding in agreement with the memory disturbances reported in E2+ PTSD patients (Freeman et al, 2005).

ADL, a measurement of a patient's functional status, are often hindered during PTSD (Zatzick et al, 2008). In mice, nest building has been used to assess distress and suffering, as well as hippocampal damage (Deacon et al, 2002) and neurodegeneration (Cramer et al, 2012; Wesson and Wilson, 2011), and may share neuropsychiatric features with measures of ADL (Deacon, 2012; Jirkof, 2014). We observed diminished nest building behavior in E2/E2 mice 2 days after fear conditioning. Following CVS, deficits were present in all groups, but the effect was most pronounced in E2/E2 and E2/ E3 mice. PTSD is also associated with sleep disturbances (Germain et al, 2008). APOE gene expression and protein levels fluctuate daily (Shen et al, 2009) and a patient's circadian rhythm and sleep quality also appear to be modulated by APOE, at least in AD (Lim et al, 2013; Robertson et al, 2005; Yeasavage et al, 2004). CVS disrupted the normal activity patterns of all mice, but this effect was most pronounced in E2/E2 and E2/E3 mice. Especially important may be the increase in activity during the normal inactive (light) cycle, which may reflect sleep disturbances in the E2/E2 and E2/E3 mice. Although translation of nest building and circadian activity to the human condition is complex, these data suggest that E2/E3 and E2/E2 mice are particularly reactive to trauma. Although we did not observe any disruption in circadian rhythm in E2/E3 veterans with PTSD, at least as measured by sleep quality and disturbances (Supplementary Table 1), future studies using more sophisticated methods to analyze circadian rhythm in E2+ patients with PTSD may be warranted.

A possible link between apoE biology and the psychiatric features of PTSD involves the HPA axis (Freeman et al, 2005; Raber et al, 2000). Low cortisol levels have been frequently reported in PTSD patients (Young and Breslau, 2004; Wahbeh and Oken, 2013). However, the effects of APOE on cortisol levels in humans (Fiocco et al, 2008; Peskind et al, 2001) and mice (Raber et al, 2000; Reverte et al, 2014; Robertson et al, 2005; Thorngate et al, 2002) are less clear. Additionally, several studies have shown varying results when examining the relationship between $A P O E$ and cortisol on stress and cognitive function (Beluche et al, 2010; Gallagher-Thompson et al, 2001; Gerritsen et al, 2011; Lee et al, 2008). Looking beyond basal levels of cortisol, Yehuda et al (2005) showed that the normal circadian rhythm of cortisol levels is flattened in Holocaust survivors with PTSD compared with non-exposed subjects. Interestingly, we observed a similar phenomenon in E2/E3 veterans with PTSD. In contrast to E3/E3 and E3/E4, cortisol levels in E2/ E3 individuals did not increase within $30 \mathrm{~min}$ of waking. Although our study is limited in power owing to the small number of cortisol samples from E2/E3 patients $(n=8)$, this apparent flattening of diurnal cortisol levels may point to pre-existing alterations in HPA axis function in E2/E3 
individuals, or may instead reflect an E2-specific physiologic response to PTSD. Although we did not observe any differences in basal cortisol levels, mice with E2 tended to have larger stress-induced increases in cortisol. Additionally, we observed a substantial increase in adrenal gland mass following CVS, an effect that was magnified in E2/E2 and E2/ E3 mice. Chronic and psychosocial stress in rodents often leads to increases in adrenal weight and could indicate a chronically active HPA axis (Herman et al, 1995; Ulrich-Lai et al, 2006). Perhaps, the lower receptor binding affinity (and elevated circulating concentrations of apoE in E2+ mice (Sullivan et al, 1998) and humans (Schiele et al, 2000) leads to altered signaling and impaired responsiveness in the regulation of steroidal synthesis.

Taken together, these data are consistent with evidence suggesting that genetic variability contributes to disparities in risk and severity of PTSD (Pitman et al, 2012; Yehuda et al, 2011), and in particular with the identification of APOE as one of these genetic markers (Freeman et al, 2005; Kim et al, 2013). In a group of chronic, combat-related PTSD subjects $(n=44)$, Freeman et al (2005) demonstrated an association between possession of E2 and more severe re-experiencing symptoms and poorer performance on several memory tests (1). Kim et al (2013) showed that allele frequencies differed between patients with PTSD and matched controls, with significantly more E2 carriers in the PTSD group $(n=128)$. Conversely, Lyons et al (2013) showed an interaction between E4 and combat exposure on PTSD symptomatology in veterans with PTSD $(n=39)$. Here, we report that in a group of 92 combat veterans diagnosed with PTSD, individuals with E2/E3 genotype had more severe PTSD symptoms compared with E3/E3 and E3/E4 participants, scoring higher on both the CAPS and PCL diagnostics. Discrepancies between these studies may be because of differences in participant age, combat exposure, severity of PTSD symptoms, the presence of comorbidities, or sample size limitations on the number of available E2 carriers for analysis. Additionally, although a TBI diagnosis was an exclusion criterion of our study, there could be the commonly comorbid, and potentially confounding influence, of physical trauma without loss of consciousness in combatants. As E4 is a predictor of poorer recovery following TBI, apoE isoform might modulate the response to physical trauma such as blast exposure in the absence of loss of consciousness as well (Shi et al, 2014; Zhou et al, 2008).

Outside the association with PTSD, APOE has a role in several neurological disorders, which may share pathologic features with PTSD, such as TBI, anxiety, and memory loss. Interestingly, E4 is associated with increased risk and/or severity in all these disorders (Raber et al, 2003; Verghese et al, 2011; Zhou et al, 2008). When considering the protective role of $\mathrm{E} 2$ in $\mathrm{AD}$ (Farrer et al, 1997), in combination with the increase in PTSD symptomatology in $\mathrm{E} 2+$ humans and mice we present here, perhaps it is appropriate to think E2 as the effective 'remembering' isoform and E4 as the 'forgetting' counterbalance. One potential mechanism by which APOE genotype may influence PTSD pathology is through differences in central nervous system (CNS) apoE protein levels. This possibility is particularly interesting given that we observed differences in plasma apoE concentrations in our cohort of veterans with PTSD. APOE genotype has previously been shown to effect plasma apoE concentrations (Larson et al, 2000). However, to the best of our knowledge, this is the first demonstration of this effect within a cohort of PTSD patients. A longstanding question in the field of dementia is the relative contribution of apoE isoform $v s$ apoE concentration in $\mathrm{AD}$ pathogenesis (Johnson et al, 2014), that is, whether it is the type or amount of apoE that is important. Could a similar query be of value in the context of PTSD? Variations in apoE levels or apoE function could affect a myriad of neurological processes important for memory, including synaptic plasticity, control of long-term potentiation, injury repair, neuroinflammation, and metabolism (Rogers and Weeber, 2008; Kim et al, 2014). Several of these pathways have been proposed to have a major role in extinction (Maren, 2014), and understanding the role apoE has in these neuronal processes may provide a framework for understanding its influence in the context of PTSD. Future studies designed to investigate apoE concentrations and function in the CNS of patients with PTSD, including cerebrospinal fluid and implicated brain regions such as the amygdala and hippocampus, may provide answers to these critical questions.

In summary, our data demonstrate a significant increase in PTSD severity and changes in cortisol levels in veterans with E2. Additionally, deficits in fear extinction, cognitive impairment, increased anxiety, altered nest building, and disruptions in circadian activity suggest a heightened sensitivity to trauma-induced behavioral abnormalities in mice with E2. The majority of people exposed to trauma do not develop PTSD, and individual differences in susceptibility to the disorder may stem from genetic variability. If PTSD is viewed as a condition in which a positive trajectory of recovery from trauma is obstructed, then identification of these points of susceptibility is imperative. Our data suggest that E2 may serve as one such biomarker of susceptibility. Subsequent studies designed to better understand the biological mechanisms by which E2 modifies the psychological and physiological response to trauma may help guide future approaches to treating PTSD.

\section{FUNDING AND DISCLOSURE}

LAJ was supported by NIEHS Grant T32-ES07060, NIH Grant T32-HL094294, and NSF Postdoctoral Fellowship SMA-1408653. HW was supported by NIH Grant K01AT004951.The content of this manuscript is solely the responsibility of the authors and do not necessarily represent the official views of the NIH or NSF. EB was supported by a Miller Fellowship through Lewis and Clark College, Portland, OR. The authors declare no conflict of interest.

\section{ACKNOWLEDGMENTS}

We thank Alicia Callejo-Black, Eduardo Tellez, Massara Eiwaz, Blair Stewart, and Reid Olsen for their invaluable technical assistance and Charles $\mathrm{N}$ Allen for his assistance with the interpretation of the circadian activity data.

\section{REFERENCES}

American Psychiatric Association (2013). Diagnostic and Statistical Manual of Mental Disorders5th ednAmerican Psychiatric Association: Arlington, VA. 
Beluche I, Carriere I, Ritchie K, Ancelin ML (2010). A prospective study of diurnal cortisol and cognitive function in communitydwelling elderly people. Psychol Med 40: 1039-1049.

Caselli RJ, Reiman EM, Locke DE, Hutton ML, Hentz JG, HoffmanSnyder C et al (2007). Cognitive domain decline in healthy apolipopro-tein E 4 homozygotes before the diagnosis of mild cognitiveimpairment. Arch Neurol 64: 1306-1311.

Cornelis MC, Nugent NR, Amstadter AB, Koenen KC (2010). Genetics of post-traumatic stress disorder: review and recommendations for genome-wide association studies. Curr Psychiatry Rep 12: 313-326.

Cramer PE, Cirrito JR, Wesson DW, Lee CY, Karlo JC, Zinn AE et al (2012). ApoE-directed therapeutics rapidly clear $\beta$-amyloid and reverse deficits in AD mouse models. Science 335: 1503-1506.

Deacon RM, Croucher A, Rawlins JN (2002). Hippocampal cytotoxic lesion effects on species-typical behaviours in mice. Behav Brain Res 132: 203-213.

Deacon RM (2006). Assessing nest building in mice. Nat Protoc 1: $1117-1119$.

Deacon R (2012). Assessing burrowing, nest construction, and hoarding in mice. J Vis Exp e2607.

Farrer LA, Cupples LA, Haines JL, Hyman B, Kukull WA, Mayeux R et al (1997). Effects of age, sex, and ethnicity on the association between apolipoprotein E genotype and Alzheimer disease. A meta-analysis. APOE and Alzheimer Disease Meta Analysis Consortium. JAMA 278: 1349-1356.

Fendt M, Endres T (2008). 2,3,5-Trimethyl-3-thiazoline (TMT), a component of fox odor - just repugnant or really fear-inducing? Neurosci Biobehav Rev 32: 1259-1266.

Fiocco AJ, Poirier J., Joober R., Nair NP, Lupien SJ (2008). Acute and long-term associations between ApoE genetic polymorphism, cortisol levels, and declarative memory performance in older adults. Psychoneuroendocrinology 33: 625-633.

Freeman T, Roca V, Guggenheim F, Kimbrell T, Griffin WS (2005). Neuropsychiatric associations of apolipoprotein $\mathrm{E}$ alleles in subjects with combat-related posttraumatic stress disorder. $J$ Neuropsychiatry Clin Neurosci 17: 541-543.

Gadermann AM, Alonso J, Vilagut G, Zaslavsky AM, Kessler RC (2012). Comorbidity and disease burden in the National Comorbidity Survey Replication (NCS-R). Depress Anxiety 29: 797-806.

Galea S, Vlahov D, Resnick H, Ahern J, Susser E, Gold J et al (2003). Trends of probable post-traumatic stress disorder in New York City after the September 11 terrorist attacks. Am J Epidemiol 158: 514-524.

Gallagher-Thompson D, O'Hara R, Simmons A, Kraemer HC, Murphy GM Jr (2001). Apolipoprotein E epsilon4 allele affects the relationship between stress and depression in caregivers of patients with Alzheimer's disease. J Geriatr Psychiatry Neurol 14: 115-119.

Germain A, Buysse DJ, Nofzinger E (2008). Sleep-specific mechanisms underlying posttraumatic stress disorder: integrative review and neurobiological hypotheses. Sleep Med Rev 12: 185-195.

Gerritsen L, Comijs HC, Deeg DJ, Penninx BW, Geerlings MI (2011). Salivary cortisol, APOE- $\varepsilon 4$ allele and cognitive decline in a prospective study of older persons. Neurobiol Aging 32: $1615-1625$

Gil-Bea FJ, Aisa B, Solomon A, Solas M, del Carmen Mugueta M, Winblad B et al (2010). HPA axis dysregulation associated to apolipoprotein E4 genotype in Alzheimer's disease. J Alzheimers Dis 22: 829-838.

Goswami S, Rodríguez-Sierra O, Cascardi M, Paré D (2013). Animal models of post-traumatic stress disorder: face validity. Front Neurosci 7: 89.

Herman JP, Adams D, Prewitt C (1995). Regulatory changes in neuroendocrine stress-integrative circuitry produced by a variable stress paradigm. Neuroendocrinology 61: 180-190.
Hostage CA, Roy Choudhury K, Doraiswamy PM, Petrella JR (2013). Alzheimer's disease neuroimaging initiative. Dissecting the gene dose-effects of the APOE $\varepsilon 4$ and $\varepsilon 2$ alleles on hippocampal volumes in aging and Alzheimer's disease. PLoS One 8: e54483.

Jirkof P (2014). Burrowing and nest building behavior as indicators of well-being in mice. J Neurosci Methods 234: 139-146.

Johnson LA, Olsen RH, Merkens LS, DeBarber A, Steiner RD, Sullivan PM et al (2014). Apolipoprotein E-low density lipoprotein receptor interaction affects spatial memory retention and brain ApoE levels in an isoform-dependent manner. Neurobiol Dis 64: 150-162.

Jovanovic T, Norrholm SD, Fennell JE, Keyes M, Fiallos AM, Myers KM et al (2009). Posttraumatic stress disorder may be associated with impaired fear inhibition: relation to symptom severity. Psychiatry Res 15: $151-160$.

Jovanovic T, Ressler KJ (2010). How the neurocircuitry and genetics of fear inhibition may inform our understanding of PTSD. Am J Psychiatry 167: 648-662.

Kaouane N, Porte Y, Vallée M, Brayda-Bruno L, Mons N, Calandreau L et al (2012). Glucocorticoids can induce PTSDlike memory impairments in mice. Science 335: 1510-1513.

Kessler RC, Berglund P, Demler O, Jin R, Merikangas KR, Walters EE (2005). Lifetime prevalence and age-of-onset distributions of DSM-IV disorders in the national comorbidity survey replication. Am Med Assoc 62: 593-602.

Kessler RC, Sonnega A, Bromet E, Hughes M, Nelson CB (1995). Posttraumatic stress disorder in the national comorbidity survey. Arch Gen Psychiatry 52: 1048-1060.

Kilpatrick DG, Resnick HS, Milanak ME, Miller MW, Keyes KM, Friedman MJ (2013). National estimates of exposure to traumatic events and PTSD prevalence using DSM-IV and DSM-5 criteria. J Trauma Stress 26: 537-547.

Kim J, Yoon H, Basak J, Kim J (2014). Apolipoprotein E in synaptic plasticity and Alzheimer's disease: potential cellular and molecular mechanisms. Mol Cells 37: 767-776.

Kim TY, Chung HG, Shin HS, Kim SJ, Choi JH, Chung MY et al (2013). Apolipoprotein E gene polymorphism, alcohol use, and their interactions in combat-related posttraumatic stress disorder. Depress Anxiety 30: 1194-1201.

Knouff C, Hinsdale ME, Mezdour H, Altenburg MK, Watanabe M, Quarfordt SH et al (1999). ApoE structure determines VLDL clearance and atherosclerosis risk in mice. J Clin Invest 103: $1579-1586$

Larson IA, Ordovas JM, DeLuca C, Barnard JR, Feussner G, Schaefer EJ (2000). Association of apolipoprotein (Apo)E genotype with plasma apo E levels. Atherosclerosis 148: 327-335.

Laskowitz DT, Horsburgh K, Roses AD (1998). Apolipoprotein E and the CNS response to injury. J Cereb Blood Flow Metab 18: $465-471$.

Lee BK, Glass TA, Wand GS, McAtee MJ, Bandeen-Roche K, Bolla KI et al (2008). Apolipoprotein E genotype, cortisol, and cognitive function in community-dwelling older adults. Am J Psychiatry 165: 1456-1464.

Lim AS, Yu L, Kowgier M, Schneider JA, Buchman AS, Bennett DA (2013). Modification of the relationship of the apolipoprotein E $\varepsilon 4$ allele to the risk of Alzheimer disease and neurofibrillary tangle density by sleep. JAMA Neurol 70: 1544-1551.

Lyons MJ, Genderson M, Grant MD, Logue M, Zink T, McKenzie R et al (2013). Gene-environment interaction of ApoE genotype and combat exposure on PTSD. Am J Med Genet B 162B: 762-769.

Mahley RW, Rall SC Jr (2000). Apolipoprotein E: far more than a lipid transport protein. Annu Rev Genom Hum Genet 1: 507-537.

Maren S (2001). Neurobiology of Pavlovian fear conditioning. Annu Rev Neurosci 24: 897-931 review.

Maren S (2014). Out with the old and in with the new: synaptic mechanisms of extinction in the amygdala. Brain Res pii: S0006-8993. 
McGuire J, Herma JP, Horn PS, Sallee FR, Sah R (2010). Enhanced fear recall and emotional arousal in rats recovering from chronic variable stress. Physiol Behav 101: 474-482.

Olsen RH, Agam M, Davis MJ, Raber J (2012). ApoE isoformdependent deficits in extinction of contextual fear conditioning. Genes Brain Behav 11: 806-812.

Peavy GM, Lange KL, Salmon DP, Patterson TL, Goldman S, Gamst AC et al (2007). The effects of prolonged stress and APOE genotype on memory and cortisol in older adults. Biol Psychiatry 62: 472-478.

Peskind ER, Wilkinson CW, Petrie EC, Schellenberg GD, Raskind MA (2001). Increased CSF cortisol in AD is a function of APOE genotype. Neurology 56: 1094-1098.

Pitman RK, Rasmusson AM, Koenen KC, Shin LM, Orr SP, Gilbertson MW et al (2012). Biological studies of post-traumatic stress disorder. Nat Rev Neurosci 13: 769-787.

Raber J, Akana SF, Bhatnagar S, Dallman MF, Wong D, Mucke L (2000). Hypothalamic-pituitary-adrenal dysfunction in Apoe $(-/-)$ mice: possible role in behavioral and metabolic alterations. J Neurosci 20: 2064-2071.

Raber J, Huang Y, Ashford JW (2004). ApoE genotype accounts for the vast majority of $\mathrm{AD}$ risk and $\mathrm{AD}$ pathology. Neurobiol Aging 25: 641-650.

Raber J (2007). Role of apolipoprotein E in anxiety. Neural Plast 2007: 91236 review.

Rau V, DeCola JP, Fanselow MS (2005). Stress-induced enhancement of fear learning: an animal model of posttraumatic stress disorder. Neurosci Biobehav Rev 29: 1207-1223.

Reiman EM, Chen K, Alexander GE, Caselli RJ, Bandy D, Osborne D et al (2004). Functional brain abnormalities in young adults at genetic risk for late-onset Alzheimer's dementia. Proc Natl Acad Sci USA 101: 284-289.

Reverte I, Pujol A, Domingo JL, Colomina MT (2014). Thyroid hormones and fear learning but not anxiety are affected in adult apoE transgenic mice exposed postnatally to decabromodiphenyl ether (BDE-209). Physiol Behav 133: 81-91.

Reyland ME, Gwynne JT, Forgez P, Prack MM, Williams DL (1991). Expression of the human apolipoprotein E gene suppresses steroidogenesis in mouse Y1 adrenal cells. Proc Natl Acad Sci USA 88: $2375-2379$.

Robertson J, Curley J, Kaye J, Quinn J, Pfankuch T, Raber J (2005). ApoE isoforms and measures of anxiety in probable $\mathrm{AD}$ patients and Apoe - / - mice. Neurobiol Aging 26: 637-643.

Rogers JT, Weeber EJ (2008). Reelin and apoE actions on signal transduction, synaptic function and memory formation. Neuron Glia Biol 4: 259-270.

Rubin GJ, Brewin C, Greenberg N, Simpson J, Wessely S (2005). Psychological and behavioural reactions to the bombings in London on 7 July 2005: cross sectional survey of a representative sample of Londoners. BMJ 331: 606-611.

Samuelson KW (2011). Post-traumatic stress disorder and declarative memory functioning: a review. Dialogues. Clin Neurosci 13: 346-351.

Schiele F, De Bacquer D, Vincent-Viry M, Beisiegel U, Ehnholm C, Evans A et al (2000). Apolipoprotein E serum concentration and polymorphism in six European countries: the ApoEurope Project. Atherosclerosis 152: 475-488.

Shen L, Carey K, Wang DQ, Woods SC, Liu M (2009). Foodentrained rhythmic expression of apolipoprotein E expression in the hypothalamus of rats. Brain Res 1273: 66-71.

Shi J, Han P, Kuniyoshi SM (2014). Cognitive impairment in neurological diseases: lessons from apolipoprotein E. J Alzheimers Dis 38: 1-9.
Shin LM, Rauch SL, Pitman RK (2006). Amygdala, medial prefrontal cortex, and hippocampal function in PTSD. Ann NY Acad Sci 1071: 67-79.

Smith ME (2005). Bilateral hippocampal volume reduction in adults with post-traumatic stress disorder: a meta-analysis of structural MRI studies. Hippocampus 15: 798-807.

Spijker S (2011). Neuroproteomics. Chapter 2: Dissection of Rodent Brain Regions Vol 57, pp 13-26.

Sullivan PM, Mezdour H, Aratani Y, Knouff C, Najib J, Reddick RL et al (1997). Targeted replacement of the mouse apolipoprotein $\mathrm{E}$ gene with the common human APOE3 allele enhances dietinduced hypercholesterolemia and atherosclerosis. J Biol Chem 272: 17972-17980.

Sullivan PM, Mezdour H, Quarfordt SH, Maeda N (1998). Type III hyperlipoproteinemia and spontaneous atherosclerosis in mice resulting from gene replacement of mouse Apoe with human Apoe ${ }^{\star}$. J Clin Invest 102: 130-135.

Thorngate FE, Strockbine PA, Erickson SK, Williams DL (2002). Altered adrenal gland cholesterol metabolism in the apoEdeficient mouse. J Lipid Res 43: 1920-1926.

Ulrich-Lai YM, Figueiredo HF, Ostrander MM, Choi DC, Engeland WC, Herman JP (2006). Chronic stress induces adrenal hyperplasia and hypertrophy in a subregion-specific manner. Am J Physiol Endocrinol Metab 291: E965-E973.

Verghese PB, Castellano JM, Holtzman DM (2011). Apolipoprotein $\mathrm{E}$ in Alzheimer's disease and other neurological disorders. Lancet Neurol 10: 241-252.

Wahbeh H, Oken BS (2013). Salivary cortisol lower in posttraumatic stress disorder. J Trauma Stress 26: 241-248.

Wahbeh H, Kishiyama SS, Zajdel D, Oken BS (2008). Salivary cortisol awakening response in mild Alzheimer disease, caregivers, and noncaregivers. Alzheimer Dis Assoc Disord 22: 181-183.

Wesson DW, Wilson DA (2011). Age and gene overexpression interact to abolish nesting behavior in Tg2576 amyloid precursor protein (APP) mice. Behav Brain Res 216: 408.

Yehuda R, Golier JA, Kaufman S (2005). Circadian rhythm of salivary cortisol in Holocaust survivors with and without PTSD. Am J Psychiatry 162: 998-1000.

Yehuda R, Koenen KC, Galea S, Flory JD (2011). The role of genes in defining a molecular biology of PTSD. Dis Markers 30: 67-76.

Yehuda R, LeDoux J (2007). Response variation following trauma: a translational neuroscience approach to understanding PTSD. Neuron 56: 19-32.

Yesavage JA, Friedman L, Kraemer H, Tinklenberg JR, Salehi A, Noda A et al (2004). Sleep/wake disruption in Alzheimer's disease: APOE status and longitudinal course. J Geriatr Psychiatry Neurol 17: 20-24.

Young EA, Breslau N (2004). Cortisol and catecholamines in posttraumatic stress disorder: an epidemiologic community study. Arch Gen Psychiatry 61: 394-401.

Zatzick D, Jurkovich GJ, Rivara FP, Wang J, Fan MY, Joesch J et al (2008). A national US study of posttraumatic stress disorder, depression, and work and functional outcomes after hospitalization for traumatic injury. Ann Surg 248: 429-437.

Zhou W, Xu D, Peng X, Zhang Q, Jia J, Crutcher KA (2008). Metaanalysis of APOE4 allele and outcome after traumatic brain injury. J Neurotrauma 25: 279-290.

Zofková I, Zajícková K, Hill M, Horínek A (2002). Apolipoprotein E gene determines serum testosterone and dehydroepiandrosterone levels in postmenopausal women. Eur J Endocrinol 147: 503-506.

Supplementary Information accompanies the paper on the Neuropsychopharmacology website (http://www.nature.com/npp) 
CORRECTION

\section{Correction: ApoE2 Exaggerates PTSD-Related Behavioral, Cognitive, and Neuroendocrine Alterations}

Lance A Johnson', Damian G Zuloaga ${ }^{1}$, Erin Bidiman ${ }^{1}$, Tessa Marzulla ${ }^{1}$, Sydney Weber ${ }^{1}$, Helane Wahbeh ${ }^{2}$ and Jacob Raber ${ }^{1,2,3}$

Neuropsychopharmacology (2018) 0:1; https://doi.org/10.1038/s41386-018-0261-z

Correction to: Neuropsychopharmacology; https://doi.org/10.1038/ npp.2015.95; published online 6 May 2015

Following the publication of this article the authors noted an error in Fig. 4. In sub-panels D-F, the y-axis should read "apoE (ng/ mg protein)" as opposed to "apoE (ng/ml)". The authors apologize for any inconvenience caused. The correct version of figure 4 is shown below. a

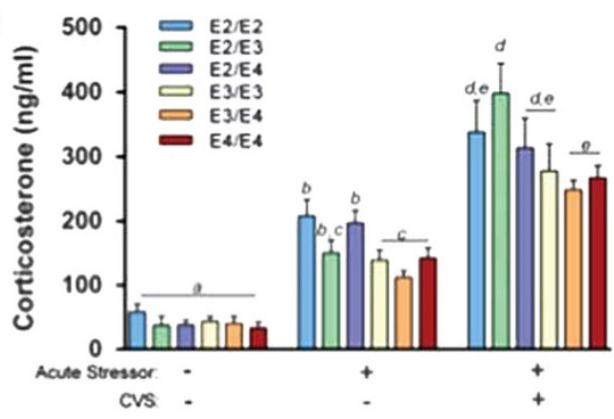

c

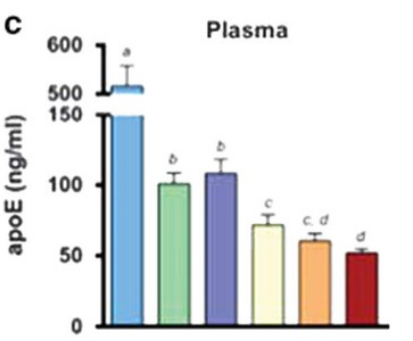

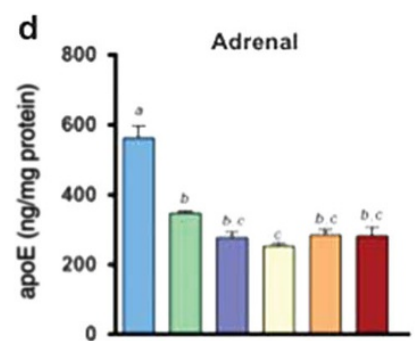
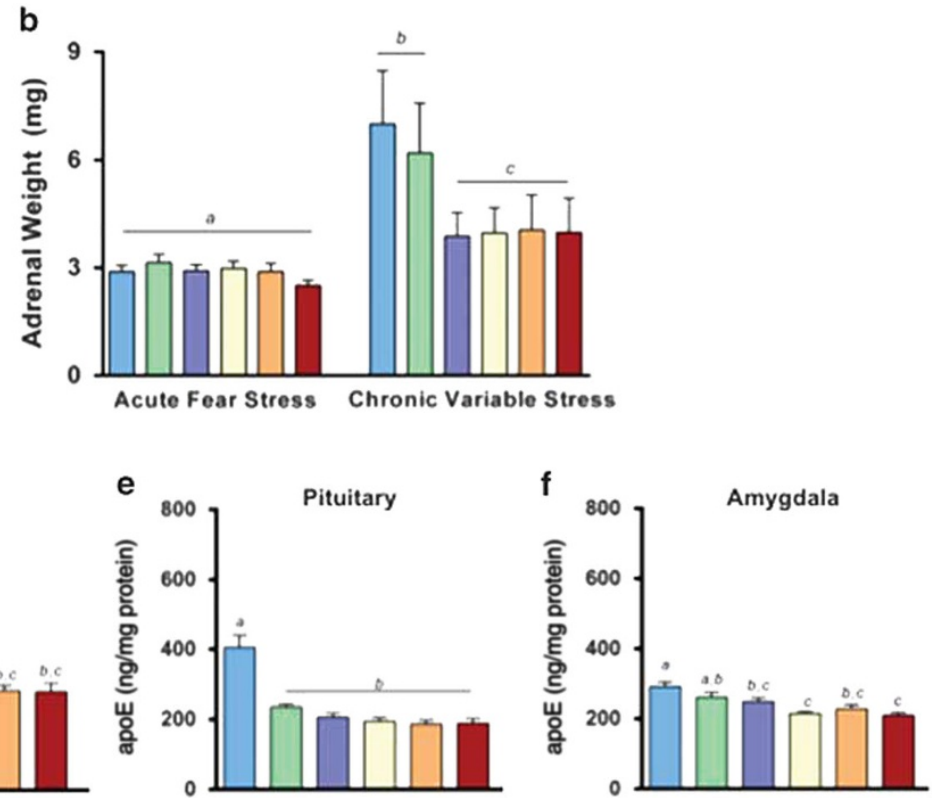

Fig. 4

\footnotetext{
${ }^{1}$ Department of Behavioral Neuroscience, Oregon Health and Science University, Portland, OR, USA; ${ }^{2}$ Department of Neurology, Oregon Health and Science University, Portland, OR, USA and ${ }^{3}$ Department of Radiation Medicine and Division of Neuroscience, ONPRC, Oregon Health and Science University, Beaverton, OR, USA Correspondence: Jacob Raber (raberj@ohsu.edu)
}

Published online: 20 November 2018 